\title{
PENGARUH INSTRUMEN MONETER KONVENSIONAL DAN INSTRUMEN MONETER SYARIAH TERHADAP PRODUK DOMESTIK BRUTO PERIODE 2012-2016
}

\author{
Try Roedyhantoro M \\ Mahasiswa Program Studi S1 Ekonomi Islam-Fakultas Ekonomi dan Bisinis-Universitas Airlangga \\ Email: try.roedyhantoro-13@feb.unair.ac.id
}

Eko Fajar Cahyono

Departemen Ekonomi Syariah-Fakultas Ekonomi dan Bisnis-Universitas Airlangga

Email: ekofajarc@feb.unair.ac.id

This study aims to determine that syariah monetary instruments and conventional monetary instruments both have an effect on the Gross Domestic Product in Indonesia. This research uses quantitative approach with Vector Auto Regression (VAR) method. This research be held during January 2012 until December 2016 in Indonesia. There are 5 variables in this research, they are "Sertifikat Bank Indonesia" (SBI) and Reverse Repo "Surat Utang Negara" (SUN) to represent conventional monetary instrument, and the representative of syariah monetary instrument are "Surat Bank Indonesia Syariah" (SBIS) and Reverse Repo "Surat Berharga Syariah Negara" (SBSN) and the last variable is Gross Domestic Product (GDP). The results of this research indicate that only SBI that has a significant positive effect on GDP. While Reverse Repo SUN, SBIS and Reverse Repo SBSN have no significant effect on GDP.

Keywords: SBI, SBIS, Reverse Repo SUN, Reverse Repo SBSN, Monetary

\section{Pendahuluan}

\section{Latar Belakang}

Sektor riil merupakan representasi dari kesejahteraan suatu masyarakat karena sektor riil merupakan gambaran besarnya jumlah produksi suatu barang dan jasa dalam suatu wilayah tertentu. Ketika tingkat produktivitas suatu negara meningkat maka hal tersebut akan berpengaruh terhadap peningkatan Produk Domestik Bruto (PDB). Hal ini sejaan dengan apa yang dikemukan Samuelson dan Nordhaus (2005) bahwa PDB adalah alat ukur untuk menilai performa perekonomian secara keseluruhan.

Tabel 1.1

PDB Indonesia Seri 2010 Menurut Pengeluaran dengan Harga Konstan 2010 (Dalam Milyar Rupiah)

\begin{tabular}{|l|l|l|l|}
\hline Periode & PDB & $\begin{array}{l}\text { \% }(\mathbf{Q} \\
\text { to Q) }\end{array}$ & $\begin{array}{l}\text { \% (Y to } \\
\text { Y) }\end{array}$ \\
\hline 2014 Q1 & $2.058 .584,90$ & - & - \\
\hline 2014 Q2 & $2.137 .385,60$ & $3.83 \%$ & - \\
\hline 2014 Q3 & $2.207 .343,60$ & $3.27 \%$ & - \\
\hline 2014 Q4 & $2.161 .552,50$ & $-2.07 \%$ & - \\
\hline 2015 Q1 & $2.157 .848,00$ & $-0.17 \%$ & $4.82 \%$ \\
\hline 2015 Q2 & $2.238 .761,70$ & $3.75 \%$ & $4.74 \%$ \\
\hline 2015 Q3 & $2.312 .640,00$ & $3.30 \%$ & $4.77 \%$ \\
\hline 2015 Q4 & $2.273 .261,60$ & $-1.70 \%$ & $5.17 \%$ \\
\hline 2016 Q1 & $2.264 .089,70$ & $-0.40 \%$ & $4.92 \%$ \\
\hline 2016 Q2 & $2.354 .797,70$ & $4.01 \%$ & $5.18 \%$ \\
\hline 2016 Q3 & $2.428 .569,90$ & $3.13 \%$ & $5.01 \%$ \\
\hline 2016 Q4 & $2.385 .577,10$ & $-1.77 \%$ & $4.94 \%$ \\
\hline
\end{tabular}

Sumber : BPS (2017)

Dari tabel diatas dapat dilihat jika pertumbuhan ekonomi Indonesia dalam beberapa kuartal masih mengalami nilai negatif yang artinya adanya penurunan produktivitas secara agregat dalam kuartal

[1] Jurnal ini merupakan bagian dari Skripsi Try Roedyhantoro NIM 041311433202 yang diuji pada tanggal 12 Mei 2017 
Roedyhantoro, et al/Jurnal Ekonomi Syariah Teori dan Terapan Vol. 5 No. 5 Mei 2018: 362-376; PENGARUH INSTRUMEN MONETER KONVENSIONAL DAN INSTRUMEN MONETER SYARIAH TERHADAP PRODUK DOMESTIK BRUTO PERIODE 2012-2016 tersebut, yaitu kuartal ke-4 pada tahun 2014, kuartal pertama dan ke-4 pada tahun 2015, serta kuartal pertama dan ke-4 pada tahun 2016. Jika sektor riil dianggap menjadi representasi dari kesejahteraan masyarakat maka artinya kesejahteraan masyarakat Indonesia sempat menurun secara tidak langsung dalam beberapa kuartal tersebut. Jika dilihat $Y$ to $Y$ PDB Indonesia mengalami peningkatan pada setiap kuartalnya, hal ini menandakan kesejahteraan masyarakat Indonesia mengalami peningkatan pada setiap kuartalnya jika dibandingkan dengan kuartal yag sama di tahun lalu.

Kebijakan moneter tidak bisa dilepaskan dari pertumbuhan ekonomi suatu negara. Hal ini sejalan dengan apa yang disampaikan oleh Warjiyo dan Solikin dalam Rachman (2017) bahwa kebijakan otoritas moneter yang dilakukan oleh bank sentral dalam pengendalian moneter adalah untuk upaya dalam pengendalian besaran moneter dalam pencapaian kondisi perekonomian yang diinginkan suatu negara.

Indonesia menerapkan sistem moneter ganda yaitu sistem moneter konvensional dan sistem moneter syariah. Sistem moneter konvensional menggunakan unsur bunga sedangkan sistem moneter syariah menggunakan unsur ju'alah. Sistem moneter syariah tidak menggunkan unsur bunga seperti pada sistem moneter konvensioanl Karena bunga dalam islam 
Roedyhantoro, et al/Jurnal Ekonomi Syariah Teori dan Terapan Vol. 5 No. 5 Mei 2018: 362-376; PENGARUH INSTRUMEN MONETER KONVENSIONAL DAN INSTRUMEN MONETER SYARIAH TERHADAP PRODUK DOMESTIK BRUTO PERIODE 2012-2016 ke sektor riil. Kebijakan moneter berupaya untuk mencapai pertumbuhan ekonomi yang tinggi secara berkelanjutan dengan mempertahankan stabilitas harga dengan cara mengatur keseimbangan persediaan vang atau mengatur jumlah peredaran vang dengan persediaan barang agar tidak terjadi inflasi.

\section{Rumusan Masalah}

1. Apakah instrumen moneter konvensional memiliki pengaruh secara signifikan terhadap Produk Domestik Bruto?

2. Apakah instrumen moneter syariah memiliki pengaruh secara signifikan terhadap Produk Domestik Bruto?

3. Manakah diantara instrumen moneter konvensional dan instrumen moneter syariah yang memiliki pengaruh yang lebih signifikan terhadap Produk Domestik Bruto?

\section{Tujuan Penelitian}

1. Untuk mengetahui apakah instrumen moneter konvensional memiliki pengaruh secara signifikan terhadap Produk Domestik Bruto.

2. Untuk mengetahui apakah instrumen moneter syariah memiliki pengaruh secara signifikan terhadap Produk Domestik Bruto.

3. Untuk mengetahui manakah diantara instrumen moneter konvensional dan instrumen moneter syariah yang memiliki pengaruh yang lebih signifikan terhadap Produk Domestik Bruto.

\section{Landasan Teori}

\section{Pengertian Kebijakan Moneter}

Nanga (2005) menyatakan bahwa kebijakan moneter adalah proses untuk mengatur jumlah uang yang beredar di masyarakat untuk mencapai tujuan-tujuan tertentu. Kebijakan moneter pada dasarnya bertujuan untuk mencapai keseimbangan internal seperti pertumbuhan ekonomi yang tinggi, stabilitas harga, pemerataan pembangunan dan keseimbangan eksternal seperti keseimbangan neraca pembayaran serta untuk mencapai tujuan ekonomi makro lainnya. Kebijakan moneter digunakan untuk menjaga keseimbangan ekonomi dengan menggunakan instrumeninstrumennya lewat transmisi-transmisi moneter yang pertama kali melalui sektor keuangan yang kemudian secara langsung maupun tidak langsung memengaruhi sektor riil.

Riadi (2017) menggolongkan kebijakan moneter menjadi dua, yaitu:

1. Kebijakan moneter ekspansif atau yang disebut kebijakan moneter longgar yang bertujuan untuk menambah jumlah vang yang beredar guna menstimulus perekonomian yang sedang lesu dengan meningkatkan daya beli masyarakat. 
Roedyhantoro, et al/Jurnal Ekonomi Syariah Teori dan Terapan Vol. 5 No. 5 Mei 2018: 362-376; PENGARUH INSTRUMEN MONETER KONVENSIONAL DAN INSTRUMEN MONETER SYARIAH TERHADAP PRODUK DOMESTIK BRUTO PERIODE 2012-2016

2. Kebijakan moneter kontraktif atau yang disebut kebijakan moneter ketat yang bertujuan untuk mengurangi jumlah vang yang beredar guna meredam inflasi

\section{Kebijakan Moneter dalam Perspektif Islam}

Dalam kebijakan moneter Islam tidak ada instrumen Bungan karena sistem keuangan Islam yang mengharamkan adanya bunga. Sistem keuangan Islam menerapkan sistem bagi-hasil atau rugi, sehingga besarnya return atau loss dalam sistem keuangan Islam tergantung dari sektor riilnya. Jika investasi pada sektor riil lancar maka return pada sistem moneter akan meningkat (Huda dkk.,2008).

Chapra (2000) dalam bukunya Sistem Moneter Islam menyatakan bahwa ada tiga sumber ekspansi moneter dalam Islam, yaitu;

1. Kebijakan anggaran yang realistis dan tidak inflasioner. Suatu pemerintahan muslim harus mampu melaksanakan kebijakan anggaran yang konsisten dengan sasarannya

2. Deposito "derivative" dari bank komersial yang dalam sebuah sistem cadangan proporsional mewakili vang yang diciptakan oleh bank komersial dalam proses perluasan kredit dan merupakan sumber utama ekspansi moneter

3. Surplus neraca pembayaran. Walaupun kenyataannya hanya sedikit negara Islam yang memiliki surplus neraca pembayaran. Jika dalam suatu negara mengalami surplus, pengeluaran pemerintah diatur menurut kapasitas ekonomi untuk menghasilkan penawaran riil, sehingga tidak ada inflasi yang dihasilkan secara internal.

Chouwdury (2012) dalam bukunya Fundamental of Islamic Economics System menyatakan bahwa "filasafat ekonomi sebuah negara Islam didasarkan pada konsep keadilan sosial. Untuk mencapai keadilan sosial, Islam mengambil dua langkah besar: Pertama, ia mencegah konsentrasi harta di tangan sedikit orang; kedua, ia menjamin berlangsungnya distribusi kekayaan melalui aturan-aturan yang efektif.

\section{Mekanisme Transmisi Moneter}

Warjiyo (2014) menyatakan bahwa Mekanisme transmisi kebijakan moneter pada dasarnya menggambarkan bagaimana kebijakan moneter yang ditempuh oleh bank sentral untuk memengaruhi berbagai aktivitas ekonomi dan keuangan sehingga pada akhirnya dapat mencapai tujuan akhir moneter. Secara lebih spesifik, mekanisme transmisi kebijakan moneter dapat diartikan proses kebijakan moneter yang bertujuan untuk memengaruhi Produk Domestik Bruto (PDB) riil dan inflasi (Taylor, 1995). 
Roedyhantoro, et al/Jurnal Ekonomi Syariah Teori dan Terapan Vol. 5 No. 5 Mei 2018: 362-376; PENGARUH INSTRUMEN MONETER KONVENSIONAL DAN INSTRUMEN MONETER SYARIAH TERHADAP PRODUK DOMESTIK BRUTO PERIODE 2012-2016

Saluran Transmisi Moneter

Mishkin (1995) menjabarkan lima saluran moneter sebagai berikut;

1. Saluran Uang

Transmisi moneter lewat saluran vang pada dasarnya menggambarkan hubungan yang jelas antara pertumbuhan perputaran uang dan inflasi yang dikemukakan oleh Fisher dengan persamaan sebagai berikut;

$$
M V=P T
$$

Persamaan diatas dapat dijabarkan sebagai jumlah vang beredar (M) dikalikan dengan tingkat perputaran vang (V) sama dengan jumlah output riil (T) dikalikan dengan tingkat harga (P).

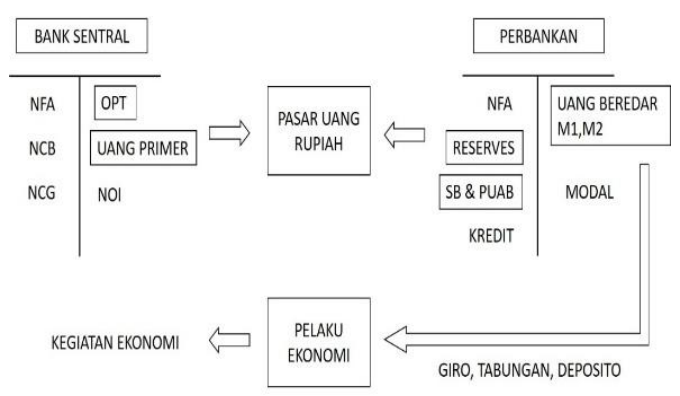

Sumber : Warjiyo (2004)

\section{Gambar 2.1 Transmisi Moneter lewat Saluran Uang}

Mekanisme transmisi moneter lewat saluran vang berawal dari tindakan Bank Indonesia untuk mengatur uang primer yang kemudian vang primer ini memengaruhi vang beredar $\mathrm{M} 1$ dan $\mathrm{M} 2$ dengan proses multiplier dan pada akhirnya vang beredar akan memengaruhi kegiatan ekonomi (Warjiyo, 2004).

\section{Saluran Kredit}

Transmisi moneter lewat saluran kredit berasumsi tidak semua bentuk simpanan masyarakat dalam vang beredar (M1 dan M2) disalurkan oleh bank melalui kredit. Artinya yang berpengaruh terhadap ekonomi riil adalah kredit perbankan, bukan simpanan masyarakat.

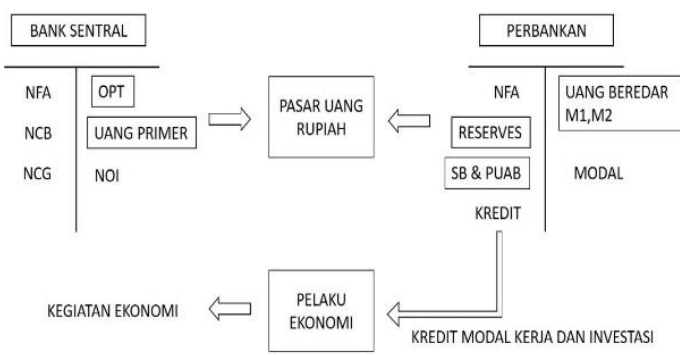

Sumber : Warjiyo (2004)

\section{Gambar 2.2 Transmisi Moneter lewat Saluran Kredit}

Perbedaan transmisi moneter saluran vang dan kredit terdapat pada asumsi peranan pasar kredit yang lebih dominan karena pasar kredit tidak selalu dalam kondisi seimbang (Warjiyo, 2004).

\section{Saluran Suku Bunga}

Transmisi moneter lewat saluran suku bunga menekankan pentingnya nilai suku bunga terhadap sektor riil. Kebijakan moneter bank sentral akan memengaruhi suku bunga yang 
Roedyhantoro, et al/Jurnal Ekonomi Syariah Teori dan Terapan Vol. 5 No. 5 Mei 2018: 362-376; PENGARUH INSTRUMEN MONETER KONVENSIONAL DAN INSTRUMEN MONETER SYARIAH TERHADAP

PRODUK DOMESTIK BRUTO PERIODE 2012-2016

kemudian memengaruhi kegiatan

perekonomian.

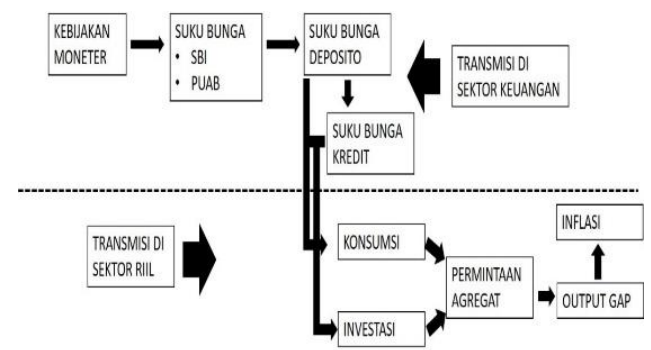

Sumber : Warjiyo (2004)

\section{Gambar 2.3 Transmisi Moneter lewat Saluran}

\section{Suku Bunga}

Transmisi moneter lewat saluran Suku Bunga melalui dua tahapan seperti yang ada di gambar diatas, yaitu tahapan transmisi di sektor moneter dan tahapan di sektor riil. Pada tahapan di sektor moneter, kebijakan bank sentral akan memengaruhi suku bunga kredit yang akan memengaruhi transmisi di sektor riil dengan hasil akhir output gap lalu inflasi (Warjiyo, 2004).

4. Saluran Harga Aset

$$
\text { Kebijakan moneter juga }
$$
berpengaruh terhadap perkembangan harga-harga aset, baik harga aset finansial seperti yield obligasi dan harga saham, maupun harga aset fisik khususnya harga properti dan emas. Transmisi ini terjadi karena penanaman dana dalam portfolio investasi tidak saja berupa simpanan di bank saja, tetapi juga dalam bentuk lain, seperti obligasi, saham dan aset fisik (Warjiyo, 2004).

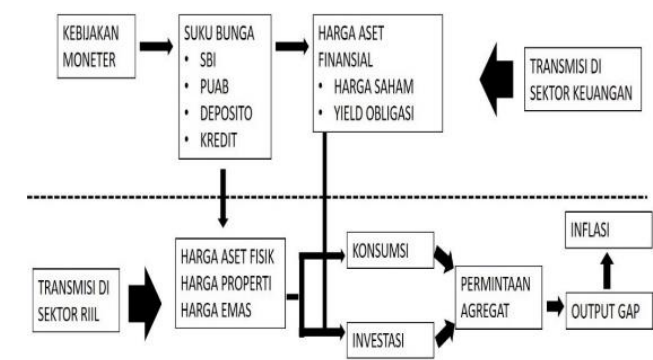

Sumber : Warjiyo (2004)

\section{Gambar 2.4 Transmisi Moneter lewat Saluran} Harga Aset

\section{Saluran Ekspektasi}

Kondisi perekonomian yang semakin tidak menentu membuat para pelaku ekonomi memertimbangkan prospek ekonomi dan keuangan di masa yang akan datang. Mereka akan membentuk presepsi tertentu terhadap perkembangan perekonomian dan kevangan. Pada akhirnya ekspektasi inflasi juga akan terbentuk dan akan memengaruhi tindakan pelaku ekonomi untuk mengambil keputusan (Warjiyo, 2004).

Mekanisme transmisi moneter lewat saluran ekspektasi dapat dijelaskan dengan gambar berikut: 
Roedyhantoro, et al/Jurnal Ekonomi Syariah Teori dan Terapan Vol. 5 No. 5 Mei 2018: 362-376; PENGARUH INSTRUMEN MONETER KONVENSIONAL DAN INSTRUMEN MONETER SYARIAH TERHADAP PRODUK DOMESTIK BRUTO PERIODE 2012-2016

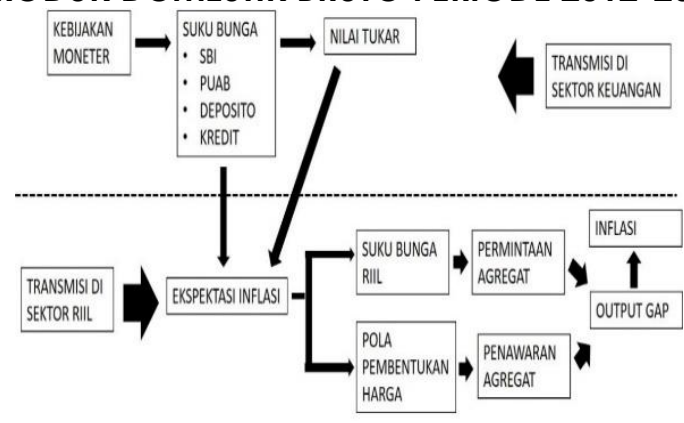

Sumber : Warjiyo (2004)

Gambar 2.5 Transmisi Moneter lewat Saluran Ekspektasi

\section{Operasi Moneter Terbuka}

Bank Indonesia diberikan wewenang dalam memberikan independensi dalam menjalankan kebijakan moneter melalui instrumen-instrumen yang digunakan yaitu melalui Operasi Pasar Terbuka (OPT) dan Standing Facilities (SF) (BI, 2017).

Operasi Pasar Terbuka (OPT) merupakan kegiatan transaksi surat berharga di pasar vang yang dilakukan bank sentral. OPT dilakukan dengan cara menerbitkan surat berharga untuk mengurangi alat-alat likuid bank-bank agar memperkecil kemampuan bank untuk memberikan kredit sehingga vang yang beredar di masyarakat dapat ditekan atau dengan cara menarik surat berharga yang sudah diterbitkan untuk menambah kemampuan bank-bank dalam memberikan kredit sehingga menambah peredaran jumlah uang. OPT dengan sistem moneter konvensional menggunakan suku bunga sebagai insentifnya sedangkan dalam OPT syariah tidak menggunakan suku bunga yang memang dilarang dalam agama islam. Hal ini sesuai dengan Firman Allah dalam QS : An-Nisa ayat 29 yang berbunyi :

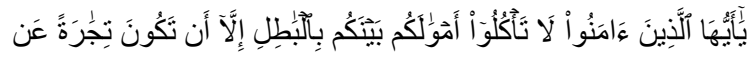

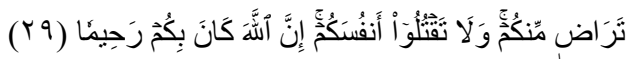

Yā ayyuhā 'I-la żīna 'āmanū lā ta'kulū amwālakum baynakum bilbāțili illā an takūna tijāratan 'an taraḍin minkum wa lā taqtulū anfusakum inna 'I-Lāha kāna bikum rahiman (29)

"Hai orang-orang yang beriman, janganlah kamu saling memakan harta sesamamu dengan jalan yang batil, kecuali dengan jalan perniagaan yang berlaku dengan suka sama-suka di antara kamu. Dan janganlah kamu membunu dirimu; Sesungguhnya Allah adalah Maha Penyayang kepadamu." (Departemen Agama RI, 2012)

\section{Variabel Operasi Pasar Terbuka Konvensional}

Bank Indonesia menggunakan instrumen Surat Bank Indonesia (SBI) dan Reverse Repo Surat Utang Negara (SUN) untuk operasi pasar terbuka Konvensional. Surat Utang Negara sendiri diterbitkan oleh pemerintah untuk membiayai APBN.

1. Sertifikat Bank Indonesia (SBI)

Sertifikat Bank Indonesia dikeluarkan oleh Bank Indonesia yang merupakan surat berharga sebagai pengakuan utang berjanga waktu pendek. Suku bunga SBI ditetapkan dengan metode tetap (fixed rate) dan harga beragam (variabel rate). Suku bunga SBI dengan harga tetap ditentukan oleh $\mathrm{BI}$ dan mengacu pada BI rate. Suku bunga SBI dengan harga beragam dihitung 
Roedyhantoro, et al/Jurnal Ekonomi Syariah Teori dan Terapan Vol. 5 No. 5 Mei 2018: 362-376; PENGARUH INSTRUMEN MONETER KONVENSIONAL DAN INSTRUMEN MONETER SYARIAH TERHADAP

PRODUK DOMESTIK BRUTO PERIODE 2012-2016

menggunakan rata-rata tertimbang. (BI,

2017)

2. Reverse Repo Surat Utang Negara (SUN)

Surat Utang Negara adalah surat berharga yang berupa surat pengakuan utang yang dijamin pembayaran bunga dan pokoknya oleh pemerintah. SUN digunakan untuk membiayai defisit APBN serta menutup kekurangan kas jangka pendek. Reverse Repo SUN adalah transaksi penjualan SUN oleh Bank Indonesia ke bank-bank umum dengan perjanjian dibeli kembali oleh BI (BI, 2017)

\section{Variabel Operasi Pasar Terbuka Syariah}

Bank Indonesia menggunakan instrumen Sertifikat Bank Indonesia Syariah (SBIS) dan Reverse Repo Surat Berharga Syariah Negara (SBSN). Sedangkan menerbitkan Surat Berharga Syariah Negara (SBSN) yang memiliki fungsi yang sama dengan SUN diterbitkan oleh pemerintah yang melalui pendekatan syariah.

1. Sertifikat Bank Indonesia Syariah (SBIS)

Sertifikat Bank Indonesia Syariah merupakan instrumen yang disiapkan khusus untuk melayani jual beli surat berharga dengan menerapkan prinsip syariah. Instrumen moneter SBIS ini diatur dalam pasal 6 PBI 10/36/PBI/2008 (BI, 2017).
2. Reverse Repo Surat Berharga Syariah Negara (SBSN)

Surat Berharga Syariah Negara (SBSN) biasa disebut Sukuk Negara adalah obligasi yang diterbitkan oleh pemerintah Republik Indonesia berdasarkan prinsip syariah. Reverse Repo SBSN adalah kegiatan penjualan SBSN oleh BI ke bank-bank syariah dengan perjanjian dibeli kembali oleh $\mathrm{BI}$ di kemudian waktu. Akad yang digunakan Bank Indonesia untuk Reverse Repo SBSN ba'i ma'a I-wa'ad (BI, 2017)

\section{Produk Domestik Bruto}

Produk Domestik Bruto (PDB) adalah total produk yang dihasilkan oleh suatu negara. Samuelson dan Nordhaus (2005) menyatakan bahwa pengukuran yang paling komprehensif untuk mengukur total output dalam sebuah perekonomian adalah Produk Domestik Bruto (PDB). PDB adalah pengukuran terhadap nilai pasar dari produk akhir barang dan jasa. Terdapat dua acara untuk mengukur PDB, yaitu dengan menggunakan harga yang berlaku pada setiap periode penghitungan dan dengan cara menggunakan harga konstan untuk semua periode yang biasanya menggunakan tahun dasar yang dinilai perekonomian dalam keadaan yang optimal. Hasil dari pengukuran PDB dengan cara yang kedua akan menghasilkan PDB riil dengan menghilangkan variabel inflasi. 
Roedyhantoro, et al/Jurnal Ekonomi Syariah Teori dan Terapan Vol. 5 No. 5 Mei 2018: 362-376; PENGARUH INSTRUMEN MONETER KONVENSIONAL DAN INSTRUMEN MONETER SYARIAH TERHADAP PRODUK DOMESTIK BRUTO PERIODE 2012-2016

\section{Metode Penelitian}

Pendekatan Penelitian

Penelitian ini menggunakan pendekatan kuantitatif deskriptif menggunakan metode Vector Auto Regression (VAR) dengan aplikasi E-views untuk melihat apakah instrumen moneter konvensional dan instrumen moneter syariah memiliki pengaruh baik dalam jangka panjang, maupun jangka pendek terhadap Produk Domestik Bruto (PDB).

\section{Jenis dan Sumber Data}

Jenis data yang digunakan dalam penelitian ini adalah data sekunder berupa runtut waktu (time series) dalam periodisasi bulanan dari bulan Januari 2012 sampai bulan Desember 2016

Sumber data dalam penelitian ini berasal dari Statistik Ekonomi dan Keuangan Indonesia (SEKI) yang ada di web resmi Bank Indonesia untuk variabel SBI, SBIS, Reverse Repo SUN dan Reverse Repo SBSN. Sedangkan untuk variabel PDB data diambil dari web resmi Badan Pusat Statistik.

\section{Teknik Analisis}

1. Uji Stasioner

Uji stasioner dalam penelitian ini menggunakan uji Augmented Dickey Fuller (ADF) dengan taraf nyata 5 persen.

2. Pemilihan Lag Optimum

Pemilihan lag optimum digunakan untuk menghilangkan autokorelasi dalam sistem VAR. Penentuan lag optimum yang tepat dapat dilakukan dengan melihat kriteria informasi yang direkomendasikan oleh Final Prediction Error (EPE), Akaike Information Criterion (AIC), Schwarz Information Criterion (SIC), dan Hannan Quinn (HQ), beberapa kriteria diatas menggunakan residual sum of square (RSS) tertimbang. Jika terdapat tanda bintang pada lag yang direkomendasikan oleh kriteria diatas, maka hal itu menunjukan lag optimal. Kritera yang mempunyai FPE atau jumlah $\mathrm{AIC}, \mathrm{SIC}$, dan $\mathrm{HQ}$ yang paling kecil merupakan lag yang digunakan.

3. Uji Kointegrasi (Johansen's Cointegration Test)

Uji kointegrasi untuk melihat keseimbangan jangka panjang di antara variabel-variabel yang diobservasi. Dalam penelitian ini menggunakan metode Johansen's Multivariate Cointegration Test.

4. Vector Error Correction Model (VECM) dan Vector Auto Regression (VAR)

Model VAR digunakan jika setidaknya ada satu variabel yang stasioner pada level atau jika tidak ada kointegrasi antar variabel yang seluruhnya stasioner pada difference yang sama. Model VECM digunakan jika seluruh variabel stasioner pada difference yang sama dan terdapat kointegrasi antar variabel.

5. Fungsi Impulse Response 
Roedyhantoro, et al/Jurnal Ekonomi Syariah Teori dan Terapan Vol. 5 No. 5 Mei 2018: 362-376; PENGARUH INSTRUMEN MONETER KONVENSIONAL DAN INSTRUMEN MONETER SYARIAH TERHADAP PRODUK DOMESTIK BRUTO PERIODE 2012-2016

Impulse response dalam penelitian

ini difokuskan untuk mengetahui respon variabel SBI, Reverse Repo SUN, SBIS dan Reverse Repo SBSN terhadap PDB. Fungsi impluse response menggambarkan tingkat laju dari dari shock variabel yang satu terhadap variabel yang lainnya pada suatu rentang waktu tertentu, sehingga dapat dilihat lamanya pengaruh dari shock suatu variabel terhadap variabel yang lainnya sampai pengaruhnya hilang atau kembali ke titik keseimbangan.

6. Variance Decomposition

Variance Decomposition atau disebut juga forecast error variance decompotition merupakan perangkat pada model VECM dan VAR yang akan memisahkan variasi dari sejumlah variabel yang diestimasi menjadi komponen-komponen shock atau menjadi variabel innovation, dengan asumsi bahwa variabel-variabel innovation tidak saling berkolerasi. Kemudian variance decomposition akan memberikan informasi mengenai proporsi dari pergerakan pengaruh shock pada sebuah variabel terhadap shock variabel yang lain pada periode saat ini dan periode yang akan datang.

\section{HASIL DAN PEMBAHASAN}

\section{Deskripsi Hasil Penelitian}

\section{Hasil Estimasi Vector Auto Regression}

Analisis VAR dalam penelitian ini menggunakan panjang lag sebanyak dua untuk model konvensional dan 3 lag untuk model syariah. Dengan jumlah observasi sebanyak 60 buah dan alpha (a) 5\% maka nilai t-tabelnya $(a / 2, n-1)$ adalah sebesar 2,00100 . Data yang digunakan adalah data pada tingkat first difference untuk model konvensional maupun model syariah karena semua variabel baru stasioner pada first difference untuk model syariah dan tidak semua variabel stasioner pada tingkat level untuk model konvensional tetapi semua variabel untuk model konvensional stasioner pada first difference. Berikut adalah hasil estimasi uji VAR model konvensional:

\section{Tabel 4.1 Hasil Uji VAR Model Konvensional}

\begin{tabular}{|c|c|c|c|}
\hline Variabel & Koefisien & T-Statistik & Keterangan \\
\hline C & 608.6764 & 0.73988 & Tidak Signifikan \\
\hline DPDB(-1) & 0.793115 & 5.62594 & Signifikan \\
\hline DPDB(-2) & -0.107381 & -0.74614 & Tidak Signifikan \\
\hline DSBI(-1) & 0.292309 & 2.86956 & Signifikan \\
\hline DSBI(-2) & -0.104295 & -0.94936 & Tidak Signifikan \\
\hline DRR_SUN(-1) & -0.040211 & -1.50577 & Tidak Signifikan \\
\hline DRR_SUN(-2) & -0.042417 & -1.67301 & Tidak Signifikan \\
\hline
\end{tabular}

Sumber: Hasil Estimasi menggunakan Eviews 8.0

Berdasarkan hasil estimasi VAR dalam penelitian ini maka persamaan model konvensional dapat ditulis sebagai berikut:

$D P D B=0.793115 D P D B_{t-1}+0.292309 D S B I_{t-1}$

Dari tabel 4.5 didapat bahwa hanya variabel DPDB(-1) dan DSBI(-1) saja yang signifakan memiliki hubungan dengan variabel DPDB (PDB pada tingkat first difference) pada tingkat signifikansi $5 \%$. Hasil 
Roedyhantoro, et al/Jurnal Ekonomi Syariah Teori dan Terapan Vol. 5 No. 5 Mei 2018: 362-376; PENGARUH INSTRUMEN MONETER KONVENSIONAL DAN INSTRUMEN MONETER SYARIAH TERHADAP PRODUK DOMESTIK BRUTO PERIODE 2012-2016 tersebut didapat dengan meihat nilai tstatistik kedua variabel tersebut yang lebih besar dari nilai t-tabel. Variabel DPDB $(-1)$ dan DSBI(-1) memiliki hubungan yang positif terhadap DPDB dengan koefisien sebesar 0,793115 untuk variabel $\operatorname{DPDB}(-1)$ dan sebesar 0,292309 untuk variabel DSBI(-1). Artinya setiap peningkatan 1 Milyar Rupiah Variabel DPDB pada bulan lalu akan menyebabkan peningkatan Variabel DPDB pada bulan ini sebesar 0,793115 Milyar Rupiah dan setiap peningkatan 1 Milyar Rupiah variabel DSBI pada bulan lalu akan meningkatkan variabel DSBI pada bulan ini sebesar 0,292309 Milyar Rupiah.

Berikut adalah hasil estimasi VAR untuk model syariah:

Tabel 4.2 Hasil Uji VAR Model Syariah

\begin{tabular}{|c|c|c|c|}
\hline Variabel & Koefisien & T-Statistik & Keterangan \\
\hline C & 899.1387 & 0.96865 & Tidak Signifikan \\
\hline DPDB(-1) & 0.662297 & 4.57116 & Signifikan \\
\hline DPDB(-2) & 0.198229 & 1.17979 & Tidak Signifikan \\
\hline DPDB(-3) & -0.305724 & -1.98156 & Tidak Signifikan \\
\hline DSBIS(-1) & 0.533732 & 0.27737 & Tidak Signifikan \\
\hline DSBIS(-2) & 1.721833 & 1.04888 & Tidak Signifikan \\
\hline DSBIS(-3) & 1.721833 & 0.13768 & Tidak Signifikan \\
\hline DRR_SBSN(-1) & -3.226251 & -1.8073 & Tidak Signifikan \\
\hline Variabel & Koefisien & T-Statistik & Keterangan \\
\hline DRR_SBSN(-2) & -0.439194 & -0.22247 & Tidak Signifikan \\
\hline DRR_SBSN(-3) & 1.658490 & 0.93471 & Tidak Signifikan \\
\hline
\end{tabular}

Sumber: Hasil Estimasi menggunakan Eviews 8.0

Dari tabel 4.6 dapat dilihat bahwa baik variabel DSBIS (SBIS pada tingkat first difference) mapun variabel DRR_SBSN (Reverse Repo SBSN pada tingkat first signifikan terhadap variabel DPDB (PDB pada tingkat first difference). Hal tersebut dapat disimpulkan dari nilai masing-masing t-statistiknya dalam lag ke-1, ke-2 maupun ke-3 untuk variabel DSBI dan DRR_SBSN tidak ada yang lebih besar dari nilai t-tabel.

\section{Hasil Impulse Response}

$$
\text { Impulse Response Function (IRF) }
$$
dapat membantu untuk menganalisis hasil estimasi VAR. Gujarati (2003) menyatakan bahwa melalui IRF ini dapat dilihat berapa lama shock yang memengaruhi suatu variabel akibat dari variabel lainnya dan juga untuk mengetahui sampai kapan shock itu akan berlangsung hingga akhirnya hilang dan titik keseimbangan akan pulih kembali. Grafik hasil IRF untuk model konvensional adalah sebagai berikut:

Response of DPDB to Cholesky One S.D. Innovations

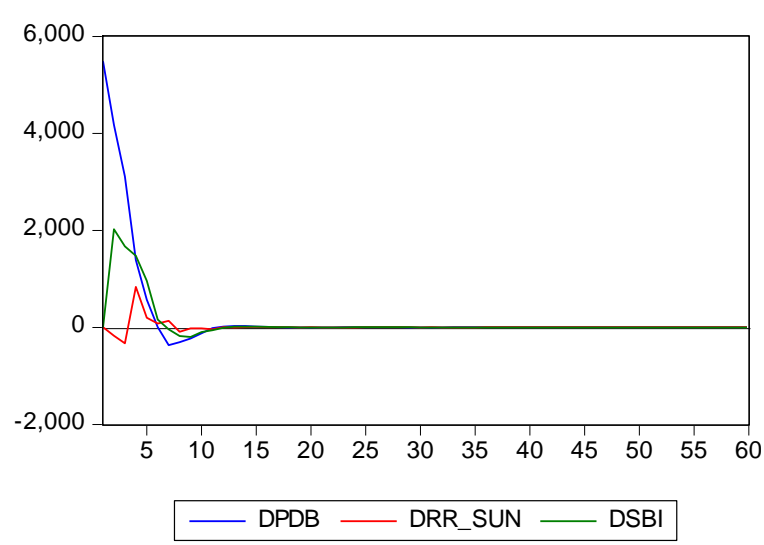

Sumber: Hasil Estimasi menggunakan Eviews 8.0

\section{Gambar 4.1 Grafik Impulse Respose Model Konvensional}


Roedyhantoro, et al/Jurnal Ekonomi Syariah Teori dan Terapan Vol. 5 No. 5 Mei 2018: 362-376; PENGARUH INSTRUMEN MONETER KONVENSIONAL DAN INSTRUMEN MONETER SYARIAH TERHADAP PRODUK DOMESTIK BRUTO PERIODE 2012-2016

Dari gambar 4.1 diketahui bahwa

Respon DPDB bermacam-macam terhadap masing-masing variabel. Variabel DSBI sendiri memberikan shock yang bernilai positif terhadap DPDB pada periode kedua hingga periode keenam dan pada periode ketujuh hingga periode keduabelas variabel DSBI memberikan shock yang bernilai negatif. Shock untuk variabel DSBI ini terhadap DPDB baru hilang pada periode kedelapanbelas. Shock terbesar untuk variabel DSBI terhadap DPDB ini terjadi pada periode kedua yang sebesar $2.021,318$

Variabel DRR_SUN memberikan shock terhadap DPDB yang lebih kecil dari pada shock DSBI terhadap DPDB. Shock terbesar dari variabel DRR_SUN terhadap DPDB adalah sebesar 835,2680 yang terjadi pada periode keempat. Shock dari Variabel DRR_SUN berfluktuatif mulai dari periode kedua sampai periode kelimabelas dan pada periode setelahnya shock tersebut sudah hilang. Shock variabel DRR_SUN bernilai negative pada periode pertama dan kedua kemudian memberikan pengaruh yang positif pada periode ketiga hingga periode ketujuh kemudian kembali memberikan shock yang negatif pada periode kedelapan hingga kesebelas.
Response of DPDB to Cholesky One S.D. Innovations

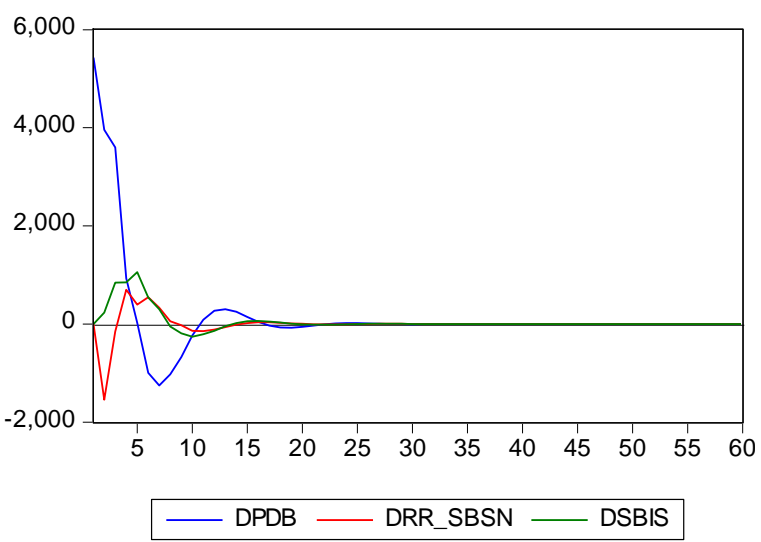

Sumber: Hasil Estimasi menggunakan Eviews 8.0

Gambar 4.2 Grafik Impulse Respose Model Syariah

Dari gambar 4.2 dapat kita lihat IRF untuk model syariah. Shock variabel DSBIS dan DRR_SBSN berfluktuatif terhadap variabel DPDB. Shock tertinggi yang bernilai positif dari variabel DSBIS adalah pada periode kelima yang sebesar 1055,108 dan shock yang tertinggi yang bernilai negatif adalah pada periode kesepuluh dengan nilai $-261,1955$. Shock variabel DSBIS mulai hilang pada periode ke-25.

Variabel DRR_SBSN memberikan shock yang bernilai negatif pada periode kedua hingga periode kedua dan ketiga yang kemudian menjadi positif pada periode keempat sampai kedelapan dan kembali menjadi negatif pada periode kesembilan hingga periode keempatbelas. Shock variabel DRR_SBSN terhadap DPDB mulai hilang pada periode ke-24. 
Roedyhantoro, et al/Jurnal Ekonomi Syariah Teori dan Terapan Vol. 5 No. 5 Mei 2018: 362-376; PENGARUH INSTRUMEN MONETER KONVENSIONAL DAN INSTRUMEN MONETER SYARIAH TERHADAP PRODUK DOMESTIK BRUTO PERIODE 2012-2016 Hasil Variance Decomposition

\section{Variance decomposition}

memberikan informasi mengenai proporsi dari pergerakan suatu variabel terhadap guncangan variabel lainnya pada periode sekarang dan periode yang akan datang. (Rachman, 2017)

Hasil Variance decomposition pada model konvensional adalah sebagai berikut:

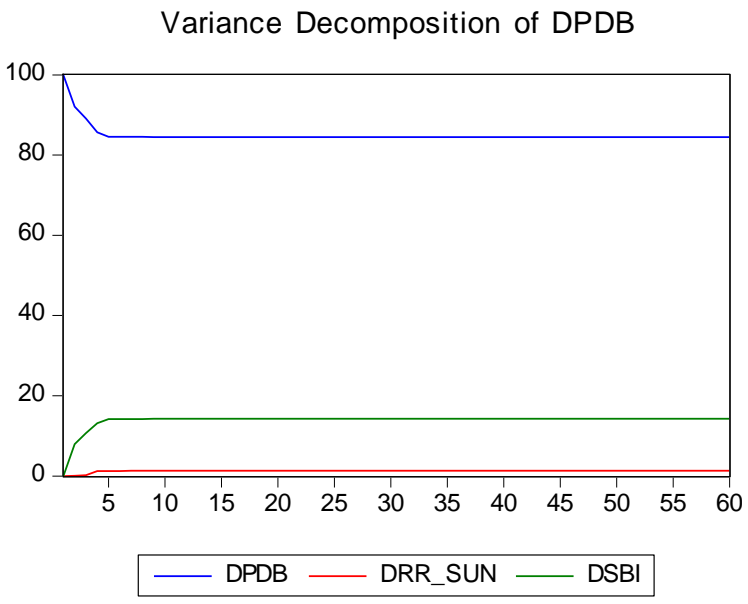

Sumber: Hasil Estimasi menggunakan Eviews 8.0

\section{Gambar 4.3 Grafik Variance Decomposition Model Konvensional}

Dari gambar 4.3 dapat ditarik kesimpulan bahwa shock variabel DSBI lebih besar ketimbang shock dari variabel DRR_SUN. shock DSBI berkontribusi 14,24\% pada DPDB dari periode kelimabelas hingga periode terakhir keenam puluh sedangkan shock variabel DRR_SUN hanya berkontribusi sebesar 1,29\% di periode yang sama dengan DSBI.

Berdasarkan hasil analisis variance decomposition tersebut, secara umum dapat disimpulkan bahwa variabel DSBI dan DRR_SUN dapat saling menjelaskan apabila terjadi shock terhadap variabel DPDB pada model konvensional. Namun porsi penjelasan masing-masing variabel masih didominasi oleh DPDB itu sendiri pada setiap periodenya.

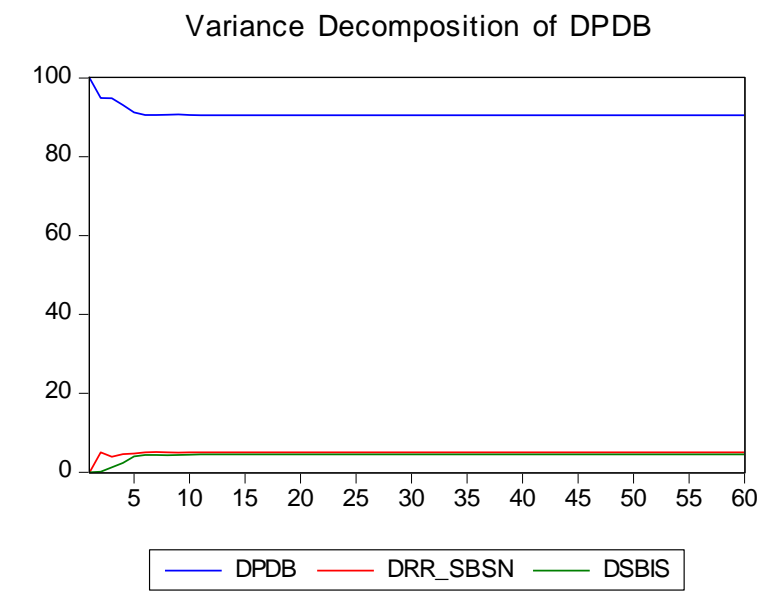

Sumber: Hasil Estimasi menggunakan Eviews 8.0

\section{Gambar 4.4 Grafik Variance Decomposition Model Syariah}

Secara Umum jika dilihat dari gambar 4.4 dapat kita lihat bahwa kontribusi shock variabel DSBIS dan DRR_SBSN tidaklah jauh berbeda. Perbedaan mencolok pada awal periode saja yang dimana pada periode kedua shock variabel DRR_SBSN berkontribusi sebesar $5 \%$ sedangkan shock variabel DSBIS hanya berkontribusi $0,1 \%$ saja. Shock kedua variabel terhadap DPDB terlihat tidak jauh berbeda pada periode keduabelas hingga akhir dimana shock variabel DSBIS adalah sebesar4,5\% sedangkan shock variabel DRR_SBSN adalah sebesar 5,02\%. Kontribusi shock variabel DRR_SBSN selalu lebih besar dari pada kontribusi variabel DSBIS dari awal 
Roedyhantoro, et al/Jurnal Ekonomi Syariah Teori dan Terapan Vol. 5 No. 5 Mei 2018: 362-376; PENGARUH INSTRUMEN MONETER KONVENSIONAL DAN INSTRUMEN MONETER SYARIAH TERHADAP PRODUK DOMESTIK BRUTO PERIODE 2012-2016 periode hingga akhir periode. Namun sama halnya dengan model konvensional, porsi penjelasan masing-masing variabel pada model syariah masih didominasi oleh DPDB itu sendiri pada setiap periodenya.

\section{SIMPULAN}

Berdasarkan hasil penelitian dan pembahasan yang telah dilakukan mengenai analisis VAR dalam hubungan instrumen moneter konvensional dan instrumen moneter syariah dengan variabel Sertifikat Bank Indonesia dan Reverse Repo Surat Utang Negara untuk instrumen konvensionalnya dan Sertifkat Bank Indonesia Syariah dan Reverse Repo Surat Berharga Syariah Negara untuk instrumen moneter syariahnya maka ditarik kesimpulan sebagai berikut:

1. SBI memiliki pengaruh secara signifikan positif terhadap PDB dan memeberikan shock kepada PDB hingga 18 bulan dan berkontribusi sebesar $14,24 \%$ dari hasil Variance Decomposition. Sedangkan Reverse Repo Surat Utang Negara tidak memiliki pengaruh yang signifikan terhadap PDB.

2. SBIS dan Reverse Repo Surat Berharga Syariah Negara keduanya tidak memiliki pengaruh yang signifikan terhadap PDB.

\section{DAFTAR PUSTAKA}

Beik, Irfan Syauqi. 2010 ,Karakter Keuangan Syariah, dalam Tsaqofi Jurnal latishodia. Institut Pertanian Bogor,

Bratadharma, A. 2016. Memahami Apa ltu Reverse Repo dan Bl Rate, (Online), (http://ekonomi.metrotvnews.com/r ead/2016/04/15/513924/memahamiapa-itu-reverse-repo-dan-bi-rate html, diakses pada tanggal 8 April 2017 pukul 21:44)

Chapra, M. Umer. 2000. Sistem Moneter Islam. Gema Insani Press. Jakarta

Chouwdury, Mausudul Alam. 1997. Money in Islam, London: Routledge.

. 2012. Fundamental of Islamic Economics System. Edisi terjemahan oleh Suherman Rosyidi. Penerbit Kencana Prenada Media Group. Jakarta

Departemen Agama RI. 2008. Al-Qur'an Terjemahan (Revisi Terbaru) dengan transliterasi Arab-Latin. Semarang CV. As-Syifa'

Dernburg, T. 1985. Macroeconomics: Concept, Theoris, and Policies. Edisi ketujuh. McGraw-Hill. New York

Friedman,M dan Anna Schwartz. 1993. A Monetary History of United States, 1867-1960. Ninth Paperback Printing Edition. Princeton University Press. New Jersey

Gujarati, D. 2003. Ekonometri Dasar. Terjemahan: Sumarno Zain, Penerbit Erlangga. Jakarta

http://www.bi.go.id/id/moneter/operasi/op erasi-pasarterbuka/Contents/Default.aspx html, diakses pada 13 April 2017

http://www.bi.go.id/id/publikasi/perkemban gan/Default.aspx html, diakses pada 13 April 2017

http://www.bi.go.id/id/statistik/seki/bulanan /Default.aspx html, diakses pada 13 April 2017 
Roedyhantoro, et al/Jurnal Ekonomi Syariah Teori dan Terapan Vol. 5 No. 5 Mei 2018: 362-376;

PENGARUH INSTRUMEN MONETER KONVENSIONAL DAN INSTRUMEN MONETER SYARIAH TERHADAP PRODUK DOMESTIK BRUTO PERIODE 2012-2016

http://www.bi.go.id/web/id/Moneter/Tujuan +Kebijakan+Moneter/ diakses pada tanggal 7 Maret 2017

Karim, Adiwarman A. 2002. Ekonomi Islam Suatu Kajian Ekonomi Makro. Jakarta: The International Institute of Islamic Thought. Indonesia,.

Khan, $M$ fahim. 1995. Essay in Islamic Economy. The Islamic Foundation. Islamic Economics Series. Leicester

Kostov,P \& John Lingard. 2000. RegimeSwitching Vector Error Correction Model (VECM). Analysis Of UK Meat.

Mankiw,N.G. 2003. Teori Makroekonomi, Terjemahaan. Jakarta: Erlangga

Mishkin, F. 1995. The Economics of Money, Banking, and Financial Markets. 4th edition, New York: Harper Collins

Nanga , M. 2005. Makroekonomi: Teori, Masalah Dan Kebijakan. Penerbit Raja Grafindo Perkasa. Jakarta

Huda, Nurul dkk. 2008. Ekonomi Makro Islam. Edisi Pertama Penerbit Kencana Prenadamedia Group. Jakarta

Rachman, S. 2017. Pengaruh Instrumen Moneter Ganda Terhadap Jumlah Uang Beredar di Indonesia pada Periode 2009-2016. Skripsi S1 Fakultas Ekonomi dan Bisnis Universitas Airlangga. Surabaya

Riadi, M. 2017. Pengertian, Tujuan dan Instrumen Kebijakan Moneter, (Online),

(http://www.kajianpustaka.com/201 7/01/pengertian-tujuan-daninstrumen-kebijakan-moneter.html, diakses pada tanggal 2 Mei 2017 pukul 12.21)

Samuelson, P and Nordhaus. 2005. Economics. Edisi ke delapan. Penerbit McGraw-Hill International Edition. New York

Sari,E. (2016). Bunga Bank Tak Banyak Turun Meski Mengacu Reverse Repo 7 Hari,

(Online)

(http://www.cnnindonesia.com/eko nomi/20160802160319-78-

148669/bunga-bank-tak-banyakturun-meski-mengacu-reverse-repo7-hari/ html, diakses 21 April 2017)

Taylor, J.B. 1995. "The Monetary Transmission Mechanism: An Empirical Framework". Journal of Economic Perspectives, 9

Warjiyo, P. 2004. Mekanisme Transmisi Kebijakan Moneter di Indonesia. Seri Kebanksentralan nomor 11. Pusat Pendidikan dan Studi Kebanksentralan (PPSK) Bank Indonesia. Jakarta 